\title{
Daniel Moyano. Desde la empresa. Firmas familiares y estructura empresarial en la industria azucarera tucumana, 1895-1930. Buenos Aires: Prometeo, 2015, 210 páginas.
}

Si in duda los estudios sobre el desarrollo de la agroindustria azucarera fueron dominantes en la historiografía socioeconómica del norte argentino en la década de 1990. Ello fue así a punto tal que la renovación historiográfica en esa región, producida en sus más importantes universidades, estuvo estrechamente vinculada a dichas investigaciones. Sin embargo, desde comienzos del nuevo siglo parecía que el interés que despertaban las cuestiones azucareras había disminuido entre los historiadores. En cambio, no ocurrió lo mismo con la densidad de tales estudios que, como parte de las miradas renovadoras en la historia económica y social, manifestaron modificaciones en sus enfoques. Un claro representante de este giro es Daniel Moyano, cuyo libro se sitúa en el cruce de la Historia de las Empresas, con la Historia de la Industria, la Historia de la Familia y la Historia de la Agroindustria Azucarera.

Tanto el período abordado en su libro como el ámbito espacial (la provincia de Tucumán), han sido de los más trabajados por los estudiosos de la agroindustria azucarera en nuestro país; no obstante, su enfoque es novedoso y sus aportes cuantiosos. Moyano ha elegido situarse en el marco de perspectivas analíticas que priorizan abordajes micro y devuelven protagonismo a los actores. Lo hace desde la Historia de la Empresa para "ofrecer nuevas claves que permitan estudiar a los empresarios en relación a sus firmas, rescatando su cultura, sus sistemas de valores y creencias, sus decisiones estratégicas y prácticas específicas", nos dice citando a María Inés Barbero y Fernando Rocchi (2004).

El autor centra la mira en tres firmas azucareras que fueron empresas familiares, cuya propiedad y control se mantuvo en el seno del núcleo de sus socios primigenios, por lo menos hasta 1930: "Avellaneda \& Terán" Sociedad Solidaria y luego Comandita por Acciones, propietaria del ingenio Los Ralos; "Compañía Azucarera Juan Manuel Terán" (pariente de los socios de la empresa anterior), dueña del ingenio Santa Bárbara que luego se convirtió en Sociedad Anónima; y "Compañía Azucarera Santa Lucía" Sociedad Anónima,

1 Unidad Ejecutora en Ciencias Sociales Regionales y Humanidades-Universidad Nacional de Jujuy/Consejo Nacional de Investigaciones Científicas y Técnicas. Argentina. Correo electrónico: aateruel13@gmail.com 
propietaria del ingenio homónimo cuyos accionistas pertenecían a distintas familias azucareras emparentadas entre sí. A lo largo del desarrollo del libro, Moyano propone poner a prueba -refutando o reafirmando- hipótesis plenas o medianamente aceptadas por la comunidad de historiadores. En este caso demuestra que, pese al ingreso de capitales extra regionales, la agroindustria azucarera se mantuvo como una actividad dominada por empresarios miembros de la burguesía azucarera tucumana.

La otra cuestión que le interesa al autor, con cuya historiografía dialoga, es la de los estudios de empresas familiares, entendidas como una estructura conformada por la superposición de tres sistemas: el familiar, el de la propiedad y el organizacional. Acertadamente, advierte que si bien en las firmas familiares -como en toda empresa- las ganancias representan el objetivo fundamental, en estos casos hay otros elementos más que entran en juego, como el prestigio social, la unión de la familia, la supervivencia, la permanencia y la longevidad. Pero Moyano no se detiene acá, a través de un prolijo análisis de la contabilidad -gracias al acceso a los archivos privados de las empresas-, incorpora indicadores económicos básicos para observar las habilidades de los directivos para asegurar el éxito de su compañía.

Los cuatro capítulos que conforman el libro tienen una lógica cronológica en su organización, esto le permite presentar las diferentes coyunturas a las que tuvieron que hacer frente las empresas del sector. Comienza con el "despegue azucarero", alrededor de 1876, y presenta el estado de las investigaciones, discute hipótesis y se adentra en el análisis de los actores empresariales de la agroindustria azucarera tucumana, tratando su origen, capitales, acceso al crédito y al poder político.

La crisis de sobreproducción de 1895 introduce el segundo capítulo, con un examen de las distintas variables que hacen a la producción, consumo y cotización de los azúcares, y la consiguiente reacción de las empresas ante la sobreoferta; aquí discute y contrapone hipótesis de diferentes autores. Finalmente, se detiene en examinar los cambios en la composición de las firmas, cerrado el ciclo de fines de siglo.

El fenómeno del paso del abarrotamiento al de la escasez, que sitúa entre 1906 y 1915, es el marco de estudio de las transformaciones de las empresas abordadas: los inicios de la formación de Sociedades Anónimas, las razones que motivaron su constitución, su composición y los mecanismos de control que aseguraban el predominio de los miembros de la familia.

El cuarto capítulo está dedicado al contexto de la crisis biológica de la caña de azúcar -debida a la plaga del "mosaico" (1915-1919)-, sus efectos sobre la producción y las respuestas del núcleo empresarial, destacándose la 
solidez del análisis financiero basado en los archivos de la contabilidad de las empresas.

Por último, la década de 1920 a 1930 -marcada por la sobreproducción-, los conflictos entre industriales y cañeros y la regulación, son aspectos que se abordan en el quinto capítulo que cierra el libro. Ese agitado período es mirado a través de las empresas y de los cambios y/o permanencias en sus estructuras.

Estamos ante una publicación inteligente, rigurosa y sólida, cuya lectura es insoslayable y aporta nuevas y frescas miradas a los estudios azucareros. La reducción de la escala de observación, conjuntamente con el análisis de casos, permite a lector acercarse a la historia de la agroindustria azucarera tucumana a partir de las problemáticas de tres empresas familiares cuya continuidad histórica dependió, en gran medida, de la presencia de capacidades empresariales dentro del seno parental. Tal como sostiene el autor, "la unidad familiar fortaleció su función de soporte cultural para articular y desarrollar un entramado de solidaridades que permitieron transferir activos inmateriales heredados a la generación de relevo, o que desarrollaron mediante un entrenamiento tácito." Así, Moyano concluye en que los casos de las empresas familiares tucumanas -semejantes al de otras burguesías regionales- permiten cuestionar las consideraciones que interpretan a la propiedad y la gestión familiar de firma como intrínsecamente retardataria o no competitiva.

Para cerrar, quiero señalar que la excelencia y seriedad del estudio de la tesis doctoral que sirvió de soporte a este libro, mereció el primer premio en el concurso de tesis doctorales (período 2010-2012) que organiza cada dos años la Asociación Argentina de Historia Económica. Saludamos esa iniciativa, la publicación de la obra y esperamos que sea el inicio de muchos libros más de Daniel Moyano.

\section{Referencia bibliográfica}

1. Barbero, M. I. y Rocchi, F. (2004). Cultura, sociedad, economía y nuevos sujetos de la Historia: empresas y consumidores. En B. Bragoni (Ed.) Microanálisis. Ensayos de historiografía argentina (pp. 103-143). Buenos Aires: Prometeo. 